\title{
Political Practice of Literary Analysis: How to read Literature more Closely
}

\author{
Mohammad Saber Khaghaninejad* \\ Department of Foreign Languages and Linguistics, Shiraz University, Shiraz, Iran \\ *E-mail address: mskhaghani@shirazu.ac.ir
}

\begin{abstract}
The development of literary/textual analysis is becoming increasingly interdisciplinary; intertextual, historically and socially-aware, and politically-motivated critical practices. This study is an attempt to show how literary/textual analyses are relied on a number of interrelated, competing and methodological political arrangements. In brief, this article is an account of the development of critically and politically-aware practices of literary analysis and implicitly inculcate that how literary analysis can be done employing political interpretations. Hence, some key concepts for critical practice of literary analysis such as interdiscourse, intertextuality, ideology negotiation and feminist/political criticisms of literature are investigated. Finally, an example of a politically committed analysis of literature is provided to show how theoretical foundations function in practice.
\end{abstract}

Keywords: Textual analysis; Literary analysis; Interdiscourse; Intertextuality; Ideology negotiation; Political interpretation

\section{INTRODUCTION}

Understanding the world is not simply a matter of end-stopped, closed-off classification of a dichotomy between object and subject. For Heidegger (1971, pp. 123125), language is not about representing something; "it performs real actions in the world of beings". Analysis sets out to understand the whole of a text from its detail, and the detail of a text from its whole (the hermeneutic circle). This is an important point to understand, because it creates a method of reading and re-reading. Understanding is a dynamic activity, an interaction or dialogue which is never fully completed, never finished, never closed off. Understanding, therefore, is not an activity which people can perform; it is not something that is done; it is a part of being, of existence, of language. In this sense it becomes antirationalist, almost mystical, and art and therefore literature assumes a status where the truth of the world speaks for itself (Eagleton, 1983). Language shows rather than tells. Telling concentrates on the idea of language as referential; showing concentrates on the idea of language as manifestation. Analysis therefore focuses not on the expression of language, but on what it means for language to speak.

What is therefore crucial about this way of thinking is that it foregrounds not the individual subject, but an interaction, a struggle, a play, where understanding and meaning can never be fixed. The ego is therefore decentred, and reality becomes a play of languages, where neither voice can ever be determined as correct or incorrect. And it is here that we have a central, fundamental contrast to the traditional empiricist preoccupation with fixed, 
determinate, unchanging meanings of text, for, there is a preoccupation with indeterminacy and with changing, dynamic, meanings of text.

For Derrida, text is a complex network of unfinished meanings, 'a fabric of traces referring endlessly to something other than itself (Derrida, 1979). The notion of text is therefore, no longer an easy, comfortable one, in which openings and endings of meaning are recognizable by readers. Its openings and endings are never actually found, and as a consequence reading becomes a much more dynamic, but an uncertain activity.

Bloom (1979) points out that 'our idealisms about texts are poor illusions' and that in practice there are no texts, just interpretations - a position that has led Hartman (1980) to argue that the critic, on reading a literary text, becomes the creator of the text. This notion opens up a crucially important, and sensitive, area in literary studies, because the difference between literature and criticism has always been controversial.

The practice of textual/literary analysis is a critical practice which argues that textual analysis as an intellectual pursuit is not, nor should it ever be, assumed to be a quest for knowledge for its own sake. It is a practice which recognizes that intellectual activity has social and political responsibilities; In short, this critical practice recognizes that analyzing literary text is first and foremost an institutional practice, requiring institutional skillssomething that teachers in most institutions often seem blissfully unaware of.

The present study focuses on the analysis of literary texts and on poetry, in particular. It is intended to draw what is considered to be some of the more distinctive philosophical, political and sociological aspects of linguistic/literary theories and practices, and their consequences for text analysis.

\section{INTERDISCOURSE AND INTERTEXTUALITY}

The developing critical literary/textual practices of the last decade or so has incorporated a number of theoretical and methodological opinions, including selected ideas of renowned theoreticians and has resulted in a markedly different analysis from traditional approaches of criticism. This developing critical practice has led to a far greater diversity of theoretical awareness, informed by a wide variety of discourses and political commitments (Harland, 1987). It has also encouraged a deconstructing of the literary canon with more and more critics turning their attention to other traditionally marginalized non-canonical texts and discourses. The consequence is that many interests and disciplines that, for many working within intrinsic criticism, were usually considered separate are now combined. Keyser (1983), for example, combined his interest in poetry with an interest in advertising in order to assess the extent to which modern advertising 'makes use of the many formal devices that literature and the visual arts do'. Or Edwards (1984) combines an interest in contemporary literary and ethnomethodological work on narrative with an interest in traditional folklore in a paper centered on joke analysis.

This is an important point and a crucial aspect of post-structuralist critical practice which follows the works of Foucault (1972). Indeed, one of the central aims of Foucault is to demonstrate that texts mean not because of their supposed 'objective' structures, but because they are the result of discursive formations "which are intricated in the ideological system of a society'. Discourse is a social process; its subjects are 'interdiscourses' determined ideologically and politically by a variety of discursive practices. This signals a use of the term 'discourse' that is quite distinct from its use in 'everyday' practice. Discourse, in this sense, indicates formations that are much larger than individual language texts: the discourse of doctor-patient relationships, the discourse of apartheid, the discourse of feminism, the discourse of educational practices, and so on. 
Analysis along these lines is therefore a political activity, in more obvious ways than theories of deconstruction; such an analysis operates on a principle that all texts are political because all discursive formations are political (Fairclough, 1988). They are political because they are (following Nietzsche) involved in power, and power is immanent in discourse. Analysis of discourse, and of the discursive practices that generate text, is therefore an analysis of history, because history is basically a series of discursive practices, each with its particular ideologies and ways of controlling power (Said, 1983). There is therefore no room, for 'objectivity' in critical practices. Knowledge is relative to a particular discursive practice that may change at a given time and in a given space. No knowledge is fixed for ever. Following Foucault, Edward Said (1983), wrote:

"Monocentrism is practiced when we mistake one idea as the only idea, instead of recognizing that an idea in history is always one among many. Monocentrism denies plurality, it totalizes structure, it sees profit where there is waste, it decrees the concentricity of Western culture instead of its eccentricity, it believes continuity to be given and will not try to understand, instead, how continuity as much as discontinuity, is made." (p. 188)

\section{IDEOLOGY NEGOTIATION THROUGH LITERATURE}

Eagleton (1976) broadly following the theories of Karl Marx, argued for a recognition that the forms of literature (for example, the novel) do not change internally; that is, they do not change as a result of some autonomous force solely within the genre, but as a result of political, social and economic pressures upon the genre (though the genre itself may not necessarily keep pace with the changes in society). Understanding meaning, therefore, is a question of recognizing social reality. Generally, a Marxist position grounds social reality in a history of struggles centered upon class and systems of production, reflecting at any given moment a dialectical relationship between history and society. The capitalist society of 'intrinsic' and 'extrinsic' criticism in the west has been founded on a base of exploitation, and as a consequence Marxist analysis of that society is effectively centered on conflict of one form or another.

Macherey (1978) based his theory of "reading the relationship of the literary text and reality" on a view which asserts that 'literature produces ideology by writing it out'. In other words, this theory assumes that ideologies need a shape, a form, in which to exist. Conflict is therefore a part of the literary text, because 'literature challenges ideology by using it' (Macherey, 1978). This is a crucial point because it focuses not just on the status of literature, but also on the status of criticism. An intrinsic understanding of interpretation implies that a text has a coherent meaning that simply needs to be discovered by the critic. Macherey (1978) argued that meaning is not simply located within the text, but is explained in terms of its larger site of production:

“...a true analysis does not remain within its object, paraphrasing what has already been said; analysis confronts the silences, the denials and the resistance in the object—not that compliant implied discourse which offers itself to discovery, but the condition which makes the work possible, which precedes the work so absolutely that it cannot be found in the work." (p.150)

Central to this approach, then, is the analysis of ideology-and crucial to any understanding of ideology is the role of language. Macherey (ibid.) did not develop this idea to any great extent, but the work of Bakhtin (1930) did. The work of Bakhtin gained 
prominence in the 1980s, mainly through the work of Kristeva (1980) and Fowler (1981), for a developing critical practice concerned with ideology.

The theory of language introduced through this article rejects the dichotomies of structuralism and argues that the text is a site for the 'negotiation of meanings'; meanings that result from a range of other texts and contexts - other 'voices'. The text is the product of social interaction and intertextualities; the basic unit of language is interactive (dialogic), 'a two-sided act' (Bakhtin, 1930). The 'sign' is multi-accented (heteroglossic), resulting in discourse as an 'arena of struggle'. Ideology for Bakhtin is 'the material embodiment of social interaction' with the emphasis upon discourse, dialogue and literature as practices rather than expressions of social reality. The subject is therefore a social subject constituted by ideology rather than by some form of rational consciousness.

\section{LANGUAGE/TEXT ANALYSIS}

Analysis requires a curiosity about the way language works in discourse, and it is this curiosity that requires an analyst not simply to describe by using a series of grammatical and linguistic labels, but to probe the language. This probing requires a quite dramatic shift of attention away from the idea that meanings are contained within the words and structures towards explaining and understanding meanings constructed by all producers of languagewriters/readers, speakers/hearers. From the beginning it seems necessary to recognize that for an analysis the analyst needs, in the first instance, to engage with (or reject) two main assumptions:

- that there is a meaning in a text 'put in' by a writer which has to be 'fished out' by the reader/hearer/critic/analyst in order for the interpretive process to take place;

- that a text can be treated as self-contained and contextless 'in its own right'.

Central to this rejection is the crucial notion that analyzing text is an activity which is concerned with understanding how a text means, not with what a text means (Norris, 1984).

Analyzing what a text means implies a position that involves finding and extracting meaning(s) from a text; it is a 'search and remove' activity. This undertaking is based on a theory that states that meanings have been 'put into' the text by the writer or speaker, and that it is the job of the reader/hearer/analyst/critic to discover them. It is effectively a static operation, and has produced over many years a wide variety of formal objective approaches, in which the personality, beliefs, background, biases of the reader/critic are considered not only irrelevant, but a positive hindrance to textual interpretation.

Analyzing how a text means involves a much more dynamic activity, whose underlying theory suggests that meanings aren't simply 'put into' a text by a writer/speaker, but are constructed by the reader/hearer. That doesn't mean that the writer/speaker has nothing to do with the text, it rather means that the only way to have of constructing a reading for a text is through our own socially determined language as reader/hearer. In other words, each time a reader reads a text, a new text is created. The reader cannot escape his own language. He cannot stop using his language in order to construct a reading of what he might consider to be someone else's text. What he constructs is his own linguistic engagement with the text-his own language, which is constructed and determined by social, cultural, ideological, and institutional forces. The American critic Harold Bloom puts it this way: 'I only know a text, any text, because I know a reading of it, someone else's reading, my own reading, a composite reading' (Bloom, 1979, p. 8).

The consequences of this position are that one's language, background, biases, ideas, beliefs, politics, and education determine his understanding. These features are socially determined by the institutions and discursive practices that constitute the social networks he 
is involved in. Consequently, whatever he constructs as a reading of a text is what he as a reader/critic has created for that text, and it is the result of critical decisions that has been developed as an integral part of his background. As analyst and critic one is not a nameless and faceless explicator of someone else's meaning. He is involved in explaining how texts mean for him and no one else. This is a crucial idea and needs to be developed further because how a text means, and who the reader is, isn't theory-less. The way he constructs meanings for texts depends on the way he constructs theories about the world, about realities.

\section{FEMINIST CRITICISM}

Analysis of literature as the product of social relations has found its strongest, and one of its most politically necessary, expressions in feminist analysis of text. When Kate Millett read the work of Lawrence as 'a progression from misogynistic homo-eroticism in 'Aaron's Rod' to the narcissistic cult of male supremacy in 'Lady Chatterley's Lover' in her book 'Sexual Politics' (Millett, 1969), she was developing in criticism a polemicism which had found a voice in De Beauvoir (De Beauvoir, 1949) and which would continue to develop in force in the 1970s and 1980s. These voices have a clear message: women are oppressed by the patriarchal order (see, for example, Eisenstein, 1979). Text analysis therefore needs to recognize that every reading is a gendered reading because all text production is gendered. Speaking/writing is not neutral/neuter.

Oppression comes not simply with the obvious patriarchal structures; it can also come with the psychological and social formation of gendered subjects, who can be disabled as objects by controlling, dominant, but often unconscious, gendered interests (Kelly-Gadol, 1976).Analysis, therefore, is concerned with the construction and deconstruction of the political, social, psychological, and historical formations and processes of gendered text (see for example, Moi, 1985, Hadigheh \& Khaghaninejad, 2013). Analysis is therefore about conflicting ideologies. Elaine Showalter argues that 'the task of feminist critics is to find a new language, a new way of reading that can integrate our intelligence and our experience, our reason and our suffering, our skepticism and our vision' (Showalter, 1985). Criticism and reading is therefore 're-visionist, it questions the adequacy of existing conceptual structures' (Godard, 1985).

Language is of course one of the major means of oppression but a difficulty arises in the creation of 'new worlds from words'. Barbara Godard (1985) asks;

"How can one be an object, be constructed by a ruling discourse and still constitute an opposition to it, be outside enough to mark an alternative? If outside, how can one be heard at all?" (p. 123).

The answer, for her as for Irigaray (1977), lies in writers who 'redraw the circle for us, shift the relationships of centre and periphery, of authoritative word and marginal silence' (Godard, 1985). The challenge to the centre is not new, but in feminist analysis and criticism it is ideologically motivated, intent on seeing the concept of difference (by which that centre has been defined for so long as an opposition between presence and absence) changed. This, then, is more than just analysis aimed at demythologizing negative images of women; it is the development of a feminist ideology, a feminist poetics (Showalter, 1985).

As part of the move towards that poetics, some feminist critics have turned their attention to the psychoanalytic work of Lacan, who argues for understanding perception by means of recognizing the split subjectivity, divided between 'being' and the 'social speaking 
self' (the split between moi/je). The ego is constructed by perception of objects; it is not 'in' the perception already. This theory is important because it argues that meaning is not 'in' anything, it is a construction, a drama (Lacan, 1977). It also enables the act of analysis to be more prominent. Freud assumed he was a neutral, innocent observer; his world was populated 'by activities without human agents', but it is exactly this human agency that feminist criticism wishes to foreground. Furthermore, meaning is not considered to be imminent in a text, which therefore motivates a feminist criticism to construct meaning, not simply to 'discover' it. Lacanian psychoanalytics does not psychoanalyse a text (as Freudian psychoanalysis does); it 'rescrutinizes' the way meanings are made (Ragland-Sullivan, 1984). Bearing this in mind, analysis of text is not just a matter of discussing certain effects of language in a text; it can be-needs to be-a powerful method for understanding the ways in which all sorts of realities are constructed through language. As Barbara Godard, cited; '...every theory of language implies a whole philosophy of history: every form of practice implies and presupposes a form of theory whose denial is a mask' (Godard, 1985, p. $165)$.

\section{POLITICAL ANALYIS}

What analysts are involved in is a socially and politically oriented explanation of language and not simply a neutral description of it. Analysts deal with the articulation of their meanings of texts, not reconstructing, by detailed surgery other people's meanings. This form of analysis is therefore a critical linguistics (Kuhn, 1962). It does not mean that writers are belittled or 'dead', or have become pointless and useless, or that their ideas and emotions are of no interest and that the writing process is of no importance at all. Far from it - what it means is that as readers we can never speak on their behalf. We often (though not always) engage with texts because of the writer, but we can only explain and articulate our own understanding of how the text means, not theirs. And this attempt at explanation is, consciously or unconsciously, ideologically determined.

The choice of text is no longer constrained by a traditional literary canon, but is very often made less because of the intrinsic (internal) value of a text, than because an analyst has an interest beyond the text. A good example is the work on a passage from Plath's The Bell Jar provided in the following lines. Central to this argument is that an analyst has to be politically committed, and this commitment cannot be conveniently put on one side while the analysis is taking place. In fact, Burton (1982), like many contemporary analysts of discourse, argued that the choice of the particular text an analyst is working on should not be arbitrary;

“...I take it as axiomatic that all observation, let alone description, must take place within an already constructed theoretical framework of socially, ideologically and linguistically constructed reality" (p. 196).

\section{SAMPLES OF LITERARY/TEXTUAL ANALYSIS}

Manipulating - editing - textually determined realities is not necessarily a conscious activity, but it can prove to be a very effective-sometimes damaging, sometimes usefulpolitical, cultural, and social strategy . In this part, the political-committed analyses of two texts (one literary prose, and a poem) are presented in which political approaches of text analysis are put into practice. This may help diagnose the real implications of a text based on its underlying deep motivations: 


\subsection{Linguistic analysis of a prose}

The article's authors worked specifically on the processes and participants of their chosen passage from 'The Bell Jar' by Palth (1978) while they were concerned with the power relations of the participants. Linguistic structures - the way realities are constructed through language - can be restructured in ways which become more or less damaging to people. Language as linguistically constructed reality can be changed to add or remove classist, sexist, and racist injustices in the world. One segment of the Plath text reads:

The wall-eyed nurse came back. She unclasped my watch and dropped it in her pocket. Then she started tweaking the hairpins from my hair.

Doctor Gordon was unlocking the closet. He dragged out a table on wheels with a machine on it and rolled it behind the head of the bed. The nurse started swabbing my temples with a smelly grease.

As she leaned over to reach the side of my head nearest the wall, her fat breast muffled my face like a cloud or a pillow. A vague, medicinal stench emanated from her flesh.

'Don't worry,' the nurse grinned down at me. 'Their first time everybody's scared to death.' I tried to smile, but my skin had gone stiff, like parchment.

Doctor Gordon was fitting two metal plates on either side of my head. He buckled them into place with a strap that dented my forehead, and gave me a wire to bite. I shut my eyes.

There was a brief silence, like an indrawn breath. Then something bent down and took hold of me, and shook me like the end of the world. Whee-ee-ee-eeee, it shrilled, through an air crackling with blue light, and with each flash a great jolt drubbed me till I thought my bones would break and the sap fly out of me like a split plant.

I wondered what terrible thing it was that I had done.

Burton (1982) gave the passage to a number of readers who responded that the patient appeared to be helpless, that she was distanced from her surroundings, and that the medical staff seemed more interested in getting the job done than in caring for her as patient. Burton looks at three things: who (or what) is "“doing" each process'; what sorts of process they are; and who the participants affected by the process are. The results are simple but effective because they immediately give a stronger image of who is doing what and when in the patient's world.

There are eight processes associated with the nurse, seven with the doctor, four with the electricity, and seven with the patient. Twenty of the thirty processes in the passage are material action intention processes, that is, they are processes in which someone intentionally does something to someone else. All of the processes associated with the nurse, the doctor, and the electricity are material action intention processes. The only material action intention process associated with the patient is when she shuts her eyes, thus shutting out the active world of the nurse, doctor and electricity. All of the processes associated with the nurse and the electricity affect the patient, but the doctor only affects the patient with one of the processes associated with him. For the rest he affects equipment.

This is a clear example of how to articulate a response that the doctor is uncaring - his concerns are with equipment rather than with the person. This is a simple analysis requiring skills in linguistic analysis in one main area, but it is also an explanation of how a text means according to a particular response. Linguistic analysis along these lines gives a vocabulary to help explain a reading. 


\subsection{Political analysis of a poem}

Mudrooroo Narogin (Colin Johnson) is an Aboriginal writer in English living in Australia. His most recent publication (after four novels) is a collection of poems, The Song Circle of Jacky and Selected Poems (Johnson, 1986). There are a number of poems in this collection which I kept returning to as a way of balancing the biased white Australian presentation of Aboriginal issues in the various media, not least at a time when Australia counts the number of Aboriginal deaths in State prisons and police lock-ups in recent years in the hundreds, and when the issue of Aboriginal land rights is still a long way from ever being justly resolved. I (the analyst) focused on a poem titled 'Encapsulated'.

\section{Encapsulated}

I

Once we wanted bread, you gave us indigestible stone;

Once we wanted bread, collected by our own hands:

Our paradise was in our being,

Our being was our paradise.

II

We were shameless,

They came and gave us shame;

We were innocent,

They came and gave us guilt.

\section{III}

Once our brains were fluid with thoughts;

Once our brains moved with the world;

Once our minds were unbounded as the land,

The sky was our resting place,

Our minds the sky of our brains.

Now we are marked by roads

Leading to towns of congealed thought;

Now our brains are laid out neatly;

Now our thoughts cannot wander;

But must keep to the highways which lead

To the imposed capital cities of their states of mind;

Even the skyways of our going lead straight on

Surveyed by the unswerving thoughts of their airplanes.

IV

Where are the roads we must follow?

Here they are, laid straight out,

Tarred and cemented, sticky with distant goals.

Where are those goals we must reach?

Here they are, thickly bound in this book,

Where are our souls which we must lead?

Here, in this church, strong-walled as a prison cell.

This poem can be read as a very powerful political statement about the oppression that has been meted out to the Aboriginal people at the hands of white Australia, though neither 
Aboriginal people nor white Australia are specifically mentioned. A particular reading can be formed, simple though it is, extrinsically, but triggered by intrinsic linguistic structures. It can be done through an interpretive process which has contextualized those triggers, and it is that process of contextualizing - what might be termed a reading formation-which forms the focus of the analysis.

\section{A) Pronoun analysis}

Issues of power and solidarity form a major part of my reading for 'Encapsulated'. These issues are triggered in the main, by pronouns. Isolated from the rest of the text they read like this:

$\begin{array}{lll}\text { we } & \text { I } \\ \text { we } & \text { our } & \text { us } \\ \text { our } & \text { our } \\ \text { our } & \text { II } \\ \text { we } & & \text { III } \\ \text { they } & \\ \text { we } & \\ \text { they } & \\ \text { our } & \\ \text { our } & \\ \text { our } & \\ \text { our } & \\ \text { our } & \\ \text { we } & \\ \text { our } & \\ \text { our } & \\ \text { their } & \\ \text { our } & \end{array}$

IV

we

they

we

they

our

we

The opening line establishes the contrast of we you us. I want to read this in terms of a time progression and feel that I can, given the prominence of the 'once' adverb. I want to read the opening line as 'Once there was 'we'; then there was 'you'; and then there will be 'us'. Power shifts hands from the original 'we' to the 'you' and then back to the 'us' - not to 'you' and 'us' but to 'us' only. The progression is made all the stronger by the fact that 'you' and 'us' are not used again. What becomes the dominant pronoun system is a contrast 
between 'we'/'our' and 'they'/ 'their'. This shift from 'you' to 'they' I think is particularly significant. Moving from second to third person pronouns is not an arbitrary meaningless move signaling different participants - it is a shift in point of view of the same participants. It is striking, I think, because it is a contrast that relies on an opposition between subject and owner. The 'we' and 'they' pronouns are subject pronouns; the 'our' and 'their' are possessive pronouns signaling ownership of one form or another.

\section{B) Nominalization analysis}

This contrast, between the 'we' and the 'they' - the subjects - and the 'ours' and 'theirs' - the owners - is a crucially important one and I read it as supported in several ways by other triggers in the poem. One of these ways is in the nominalizations. A nominalization is a phrase which functions like a single noun but which relies for its meaning on a verbal process of some description. For example, the phrase 'the imposed capital cities' in line 19 is most effectively understood in terms of a process of someone imposing something on someone.

Who is the 'someone' that does the imposing? What is the 'something'? Who is the 'someone' that has the something imposed upon them? We can answer only one of those questions with direct evidence from the text and that is that it is 'capital cities' which are imposed by someone upon someone. The 'what' is therefore answered intrinsically. The ' who' has to be answered extrinsically, though in my reading I would want to suggest that it is the 'they' who do the imposing and the 'we' who are imposed upon. The point of the nominalization is that it leaves these questions unanswered-the agents of the action and those affected by the action are often hidden from view and therefore require inferences to be made as to identities.

But there are also other significant ways of constructing meaning with nominalizations, one of which is to demonstrate the power of one participant - the agent over the other participant. For example, 'the unswerving thoughts of their aeroplanes' (line 21) are a nominalization which suggests a process, something like 'someone has made the thoughts of their aeroplanes in an unswerving way'. In other words, there is an agent who is responsible for a mode of travel (probably represent a mode of thought and culture) which is straight and unswerving. I understand a word like 'unswerving' in terms of its contrast 'swerving', i.e. a contrast between straight and non-straight. The point of the nominalization, therefore, is to suggest that the agent has created not simply straight modes of travel, or straight modes of thinking, but has created difference between the agent and the affected.

Again, the adverbs, contrasting 'once' and 'now' suggest this as a movement involving time. Importantly then, the nominalization involves the power of an agent over an affected, for example 'the skyways of our going' (line 20) involves the creation of skyways by someone - and that someone seems clearly to be the 'they' of the poem' not the 'we' - and they are created to the extent that the 'we' of the poem seems to have no choice but to follow the ways directed by the 'they'. The 'we' is therefore oppressed by the 'they', though this is often seen by the 'they' as the faults and inadequacies of the 'we' and not as a direct result of their oppressive activities, an issue which does not go unnoticed in the following poem from the same collection:

Sing sadness, sing sadness over our land;

Sing sadness, sing sadness throughout our land;

We have failed ourselves, sing sadness.

Poor Jacky Jacky tasted the wine,

And forgot his culture, his ceremonies,

Sing sadness, sing sadness, English culture, 
Sing sadness, A Dreaming from a faraway land, Where the sun does not take revenge, revenging Itself on white flesh bared in a black land;

Revenging itself on a white culture reshaping our land.

(Lord Help Us, 96)

There are roads and goals which have to be followed - roads and goals which are now a different 'Dreaming'. Where once the Aboriginal Dreaming was understood in terms of 'Our paradise was in our being, Our being was our paradise' (lines 3-4) it is now overshadowed by another Dreaming determined by white Australia - a Dreaming created by others so that 'our brains are laid out neatly' (line 16) by who? 'Our thoughts cannot wander (line 17) why not? Because the 'once' has been transformed by someone into a 'now' which is straight and foreign compared to a time when people were not constrained by this straightness, when 'our brains moved with the world' (line 10) and 'our brains were unbounded as the land' (line 11). But now 'we are marked by roads' (line 14) built by what agent? I don't have that information directly because the passive 'are marked' has the effect of hiding the agent involved. Similarly in lines 11, 16, 23 the passive hides the agent of the processes ('our minds were unbounded', 'our brains are laid out neatly', 'are laid straight out',). Of the agents involved in the passives in the text, only two seem to be associated with the 'we' (lines 9,10) while all the others seem to suggest the 'they'.

\section{C) Phrase analysis}

The adjectival phrase 'congealed thought' is most effectively understood as a verbal process because an agent is responsible for the act of congealing. The contrast, therefore, between straightness and non-straightness is an important one, because it operates very effectively as an image of oppressive change.

This text not simply as an expression of oppression, but as a political statement requires active involvement by readers to interpret the agents on both 'sides' of the division. Roberts (1971) in 'Being an Aboriginal in Australian Society' puts it like this:

"The oppression and depression thrust upon us by the governments of Australia and by the people as a whole, force us to emerge as a power structure related to politics and culture, and to all the directions that can make us a powerful pressure group in our confrontations with the Australian nation." (p. 19)

and continues:

"No matter in what direction you turn in Australia today you will find strong anti-Aboriginal attitudes, expressed in political and spiritual discriminations. There will emerge a radical group of Aborigines who will confront these attitudes on the ground that they cannot tolerate the situation and must take drastic steps to remove the blots, curses, blemishes that have so undermined and desecrated them." (p. 19)

True understanding requires a participation by the reader or listener which involves them in a dynamic process of interpretation. This is true of 'Encapsulated' too. Interpretation therefore means becoming involved in the political world of the poem, in just as active a way as would be required in a street march or rally of opposition. To concentrate on this poem as though it fitted comfortably into a literary mould by emphasizing literary effects and preoccupations would, it seems, reduce the reading from a politically radical and 
dynamic process to a passive, less politically potent reading and to put it on a par with the easy comfortableness of an uncaring white Australia.

\section{CONCLUSION}

All discourses are ideologically, textually, institutionally and politically determined. A great deal of the work undertaken by contemporary analysts aims to break down the myth that the discourse of literary studies has to be dominated by an institutional literary canon. The relationship of ideology and meaning is something that has influenced a great deal of work in language and literature studies over the last twenty years or so, and many of the theoretical influences have come from disciplines like philosophy, sociology, and political science (e,g., Ellis, 1977; Frow, 1986). Burton (1982) argues,

There is no such thing, as a-political analysis. We cannot be politically neutral in anything we do as analysts, and, as a consequence, I believe all academic work should be committed to influencing the better development and improving the rights of human beings All knowledge is ideologically determined and we are politically irresponsible if we do not recognize this. (pp.131).

The theory that language is simply a means of representation-language as saying-, is really a very inadequate one. Language does more than say; it does more than pass on information or reflect an already existing reality 'out there' somewhere in the world. Language is about action and interaction; it is about performance, about showing, about doing. Language is not a neutral instrument: it is biased in a thousand different ways, and those ways are of course determined by any number of differing ideologies, knowledge and power systems, and institutions. it is the role of a responsible critical linguistics to develop the means of understanding and explaining the mechanics of those thousand different ways. To summarize, the main implications of the study are:

- Language is a means of understanding what it means to 'be', rather than a means of expressing a 'given' reality.

- What it means to 'be' is best seen in terms of socially constructed realities rather than in terms of the world as psychologically 'real'.

- Analysis of text is therefore a dynamic activity, concerned with language as a dynamic process, not as a static product.

- Analysis therefore concentrates not just on what language says, but on what language does.

- What language does is not done through a single voice, but through a process of interaction; it is dialogic (to use Bakhtin's term), so the interactive voices, not the single, individual voice, become the focus of analysis. The ego is therefore decentred, and consequently social, institutional and textual constructions of reality are foregrounded.

- Socially constructed realities are understandable only in terms of ideological variation. Such variation inevitably means that the construction of meanings for texts is a process of indeterminacy. There are no fixed, determinate meanings encoded within the texts; texts are best understood in terms of indeterminate meanings constructed by readers.

- There is therefore no such thing as 'the single, correct, meaning of a text'. This means that the status of the writer is deprivileged, and the role of the reader, governed by 
institutional and social discourses, is given a much more prominent role in the construction of meaning.

- A critical practice informed by these factors therefore concentrates on the analysis of literary texts in terms of reading, not writing.

- This type of criticism is therefore a political act, aiming to understand not simply what a text means but how a text means.

The main goal of this sort of analysis is much larger than that of simply being able to describe linguistic or stylistic structures in texts; such analysis plays a major part in understanding the nature of language, and hence in understanding people and the discursive practices they are engaged in.

\section{Biography}

Mohammad Saber Khaghaninejad has a Ph. D in teaching English as a foreign language (TEFL) and at the moment is an assistant professor at Shiraz University, Iran. He has offered many general and technical courses at different Iranian universities for a decade now. His areas of interest are "language acquisition", "teaching methodology", "discourse analysis" and "critical discourse analysis".

\section{References}

[1] Heidegger, M. (1971). Poetry, Language, Thought. London: Harper \& Row.

[2] Eagleton, T. (1983). Literary Theory: An Introduction, Oxford: Basil Blackwell.

[3] Derrida, J. (1979). Margins of Philosophy. Brighton: Harvester Press.

[4] Bloom, H. (1979). The breaking of form. MIT Press.

[5] Hartman, G. (1980). Criticism in the Wilderness: The Study of Literature Today, New Haven: Yale University Press.

[6] Harland, R. (1987). Superstructuralism: The Philosophy of Structuralism and PostStructuralism, London: Methuen.

[7] Keyser, S.J. (1983). There is method in their adness: the formal structure of advertisement. New Literary History, 14(2), 305-34.

[8] Edwards, C.L. (1984). Stop me if you've heard this one: narrative disclaimers as breakthrough into performance. Formula, 25(3), 214-28.

[9] Foucault, M. (1972). The Archeology of Knowledge. London: Tavistock.

[10] Fairclough, N. (1988). Register, power and socio-semantic change. England: Rutledge publications.

[11] Said, E. (1983). The World, The Text, and the Critic. Cambridge. Mass.: Harvard University Press.

[12] Eagleton, T. (1976), Criticism and Ideology: A Study in Marxist Literary Theory, London: Verso.

[13] Macherey, P. (1978). A Theory of Literary Production. London: Routledge \& Kegan Paul.

[14] Bakhtin, M. (1930). Rabelais and His World. Cambridge, Mass: MIT Press. 
[15] Kristeva, J. (1980). Desire in Language: A Semiotic Approach to Literature and Art. New York: Columbia University Press.

[16] Fowler, R. (1981). Literature as Social Discourse: The Practice of Linguistic Criticism. London: Batsford.

[17] Norris, C. (1984). The Deconstructive Turn. Essays in the Rhetoric of Philosoph. London: Methuen.

[18] Millett, K. (1969). Sexual Politics. London: Virago.

[19] Eisenstein, Z.R. (1979). Capitalist Patriarchy and the Case of Social Feminism, New York: Monthly Review.

[20] Kelly-Gadol, J. (1976). The social relations of the sexes: methodological implications of women's history. Sign, 1, 809-24.

[21] Moi, T. (1985). Sexual/Textual Politics: Feminist Literary Theory, London: Methuen.

[22] Hadigheh, S. \& Khaghaninejad, M. S. (2013). How to apply critical linguistics in English/Persian literary works' criticism. International Journal of Linguistics, 5(4), 90- 108.

[23] Showalter, E. (1985). Toward a feminist poetics. Harvard University Press.

[24] Godard, B. (1985). Redrawing the circle; Power, poetics, language. Harvard University Press.

[25] Irigaray, L. (1977). Ce sexe qui n'en est pas un. Paris: Minuit.

[26] Lacan, J. (1977) Ecrits, Paris: Seuil.

[27] Ragland-Sullivan, E. (1984). The magnetism between reader and text: prolegomena to a Lacanian poetics. Poetics, 13, 381-406.

[28] Kuhn, T. S. (1962). The Structure of Scientific Revolutions. Chicago: Chicago University Press.

[29] Burton, D. (1982). Through glass darkly: through dark glasses. Carter series.

[30] Johnson, C. (1986). The Song Circle of Jacky and Selected Poems, Melbourne: Hyland House.

[31] Roberts, F. (1971). Being an Aboriginal in Australian Society' in Racism in Australia. Tasks for General and Christian Education. Melbourne Conference: Division of Christian Education.

[32] Ellis, J. (1977). Visible Fictions. London: Routledge \& Kegan Paul.

[33] Frow, J. (1986). Marxism and Literary History, Cambridge, Mass.: Harvard University Press. 